CANCER CELL

INTERNATIONAL

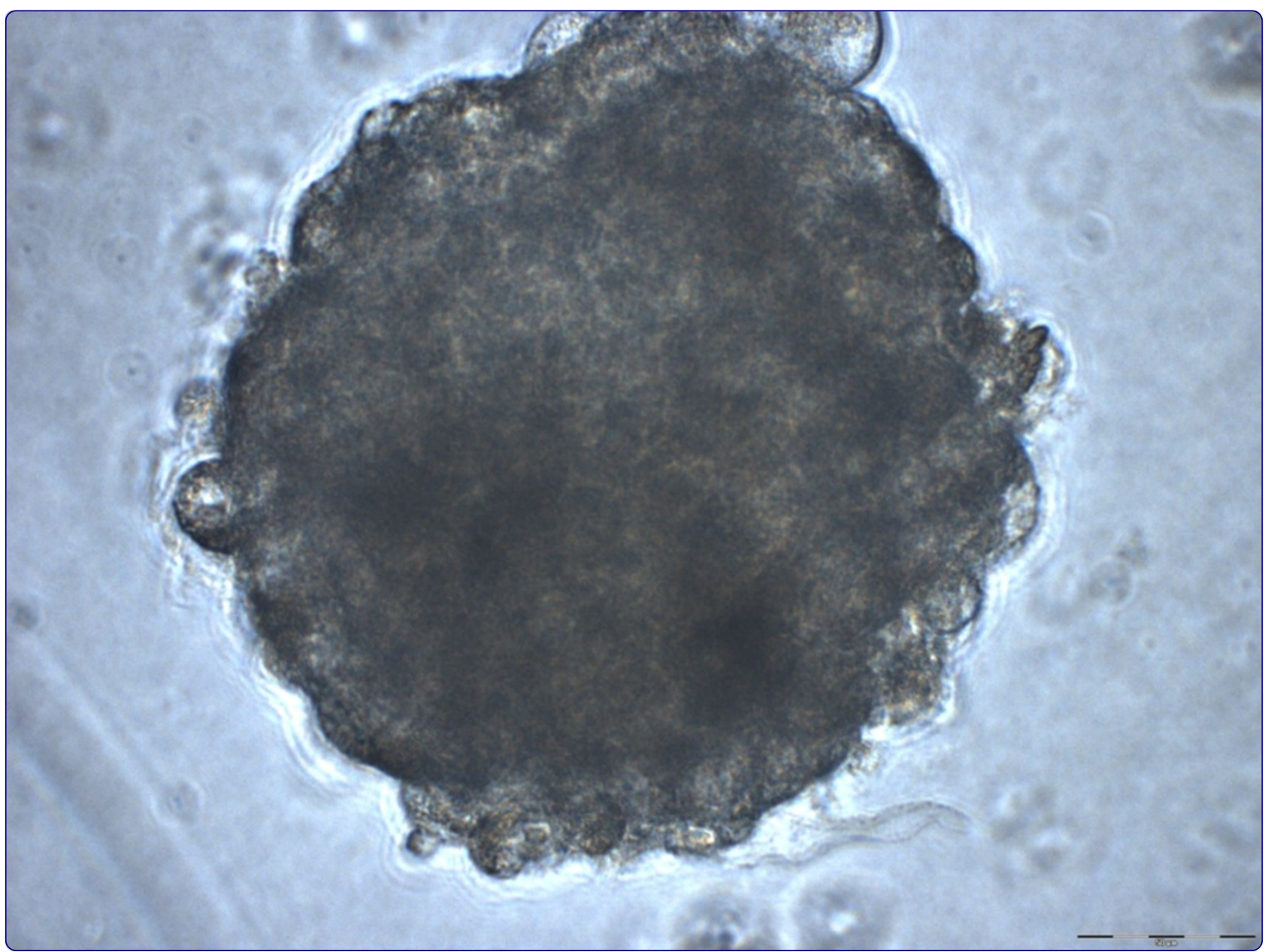

Functional features of cancer stem cells in melanoma cell lines

Zimmerer et al.

() Biomed Central

Zimmerer et al. Cancer Cell International 2013, 13:78 http://www.cancerci.com/content/13/1/78 


\title{
Functional features of cancer stem cells in melanoma cell lines
}

Rüdiger M Zimmerer ${ }^{1 *}$, Philippe Korn ${ }^{1}$, Philippe Demougin ${ }^{1,2}$, Andreas Kampmann', Horst Kokemüller ${ }^{1}$, André M Eckardt ${ }^{1}$, Nils-Claudius Gellrich ${ }^{1}$ and Frank Tavassol ${ }^{1}$

\begin{abstract}
Background: Recent evidence suggests a subset of cells within a tumor with "stem-like" characteristics. These cells are able to transplant tumors in immunodeficient hosts. Distinct from non-malignant stem cells, cancer stem cells (CSC) show low proliferative rates, high self-renewing capacity, propensity to differentiate into actively proliferating tumor cells, and resistance to chemotherapy or radiation. They are often characterized by elevated expression of stem cell surface markers, in particular CD133, and sets of differentially expressed stem cell-associated genes. CSC are usually rare in clinical specimens and hardly amenable to functional studies and gene expression profiling. In this study, a panel of heterogenous melanoma cell lines was screened for typical CSC features.
\end{abstract}

Methods: Nine heterogeneous metastatic melanoma cell lines including D10 and WM115 were studied. Cell lines were phenotyped using flow cytometry and clonogenic assays were performed by limiting dilution analysis on magnetically sorted cells. Spheroidal growth was investigated in pretreated flasks. Gene expression profiles were assessed by using real-time rt-PCR and DNA microarrays. Magnetically sorted tumor cells were subcutaneously injected into the flanks of immunodeficient mice. Comparative immunohistochemistry was performed on xenografts and primary human melanoma sections.

Results: D10 cells expressed CD133 with a significantly higher clonogenic capacity as compared to CD133- cells. Na8, D10, and HBL cells formed spheroids on poly-HEMA-coated flasks. D10, Me39, RE, and WM115 cells expressed at least 2 of the 3 regulatory core transcription factors SOX2, NANOG, and OCT4 involved in the maintenance of stemness in mesenchymal stem cells. Gene expression profiling on CD133+ and CD133- D10 cells revealed 68 up- and 47 downregulated genes (+/-1.3 fold). Two genes, MGP and PROM1 (CD133), were outstandingly upregulated. CD133+ D10 cells formed tumors in NSG mice contrary to CD133- cells and CD133 expression was detected in xenografts and primary human melanoma sections using immunohistochemistry.

Conclusions: Established melanoma cell lines exhibit, to variable extents, the typical features of CSCs. The tumorigenic cell line D10, expressing CD133 and growing in spheroids and might qualify as a potential model of melanoma CSCs.

Keywords: Cancer stem cells, CD117, CD133, CD146, CD271, Cell lines, D10, Melanoma, WM115

\footnotetext{
* Correspondence: zimmerer.ruediger@mh-hannover.de

${ }^{1}$ Department of Oral and Maxillofacial Surgery, Head \& Neck Oncology

Laboratory, Hannover Medical School, Carl-Neuberg-Str. 1, Hannover

D-30625, Germany

Full list of author information is available at the end of the article
}

\section{Biomed Central}

(c) 2013 Zimmerer et al.; licensee BioMed Central Ltd. This is an Open Access article distributed under the terms of the Creative Commons Attribution License (http://creativecommons.org/licenses/by/2.0), which permits unrestricted use, distribution, and reproduction in any medium, provided the original work is properly cited. 


\section{Background}

Malignant melanoma occurs in $5 \%$ of men and $4 \%$ of women in the Western world [1]. Patients with advanced disease have a poor prognosis with a reported median survival ranging between 3 and 11 months [2]. In stage IV of the disease, when patients suffer from inoperable recurrent tumors and regional and distant metastases, therapeutic strategies include systemic chemotherapy and chemoimmunotherapy. Interferon-alpha and immune modulators such as interleukin 2 (IL-2) and antiCTLA-4 (cytotoxic T-lymphocyte antigen-4) have shown a significant clinical benefit to the patients in some prospective randomized studies [3-6]. Although recent clinical trials using targeted therapy (vemurafenib) suggest promising results, the prognosis of patients with advanced disease remains poor [7]. In this context, the idea that tumors comprise cells endowed with stem cell-like properties, which might qualify as potential targets, is part of ongoing research. Hamburger and his group described, in 1977, that tumors comprise cells with heterogeneous tumorigenicity and differentiation potential [8]. By applying the principles of stem cell biology to cancer, many tumors have recently been shown to be organized hierarchically into clonally derived populations of cells with different tumorigenic potentials. Bonnet and colleagues [9] were the first who could phenotypically distinguish cells of acute myeloid leukemia (AML) with high tumorigenicity from the remaining tumor cells using surface markers. It was shown that only a small subset of these cells, phenotypically similar to hematopoietic stem cells, could transfer acute AML when transplanted into immunodeficient mice. It was suggested that the tumorigenic cell population represented a minority of cells within the tumor and that its isolation could be attempted from most tumors based on a unique surface marker expression pattern. In particular CD133 (Prominin 1), which is expressed on stem and early progenitor cells (CD34+ hematopoietic stem cells) and tumor-initiating cells of several malignancies $[10,11]$, is prominent subject of ongoing research. A few more properties of CSCs have been identified so far, including their common capacity to grow in anti-adhesive structures called spheroids and a higher resistance to hypoxia, possibly related to aberrant angiogenesis in rapidly expanding tumors [12,13]. Fang [14] described a subset of cells derived from freshly isolated or in vitro stabilized melanoma cell lines that was able to form "melanoma spheroids" when grown in a specific stem cell medium. Tavaluc [15] and Zhou [16] suggest that CSCs have a higher ability to survive under hypoxic conditions than normal cancer cells.

Taken together, CSCs are defined by their ability to induce tumor growth following transplantation. The tumorigenic potential of CSCs unites self-renewal and differentiation potential. Although some tumorigenic phenotypes have been identified in several solid malignancies so far, CSCs cannot be clearly defined by a certain morphology, genotype, or phenotype [17]. Current cancer therapeutics based on tumor regression may target and kill differentiated tumor cells, which compose the bulk of the tumor, while sparing the rare CSC population. The CSC model suggests that the design of new cancer therapeutics may require the targeting and elimination of CSCs. The aim of the study was to identify CSC markers potentially allowing the functional characterization of specific cell subsets from clinical specimens, which have been identified in different types of tumors, including melanoma [18]. However, the minute numbers of cells presenting these features that can be obtained from surgical samples usually prevent a thorough evaluation of the molecular pathways involved in "stemness". This background has prompted several research groups to explore the possibility of taking advantage of the relative heterogeneity of established cell lines to identify cell subsets endowed with CSC features. However, since major differences in the published xenotransplantation models do exist and the conclusion that CSCs are defined by their tumorigenic potential is still discussed controversially [19], this study focuses on the in vitro identification and characterization of stem celllike cancer cells in established melanoma cell lines. We have addressed typical phenotypical and functional CSC features in established melanoma cell lines in order to identify cellular reagents amenable to detailed molecular profiling.

\section{Results}

\section{Characterization of cell lines under investigation}

The expression of melanoma associated antigens (MAAs) was used to characterize melanoma cell lines. The antigens of interest belonged to 2 main groups: tumor-associated cancer testis antigens (MAGE-A3, NY-ESO-1) and melanoma differentiation antigens (melanosomal matrix protein (gp100), melanoma antigen recognized by $\mathrm{T}$ cells (Melan-A/MART-1), tyrosinase)). D10, WM115, and HBL cell line expressed the melanoma differentiation antigens gp100, tyrosinase, and MART-1. These genes are also expressed in nontransformed melanocytes. In contrast, cancer testis antigens (CTA) are expressed in several malignancies of different histological origin and are also expressed on a few non-neoplastic cell populations including spermatogonia and trophoblasts, but not in healthy melanocytes. Results are shown in Table 1 . The expression analysis of the regulatory core transcription factors NANOG, SOX2, and OCT4 revealed that a high NANOG expression was detectable in D10, WM115, and HBL cells. Results are shown in Table 2. 
Table 1 Expression of MAA* in melanoma cell lines

\begin{tabular}{llllll}
\hline Cell line & \multicolumn{2}{l}{$\begin{array}{l}\text { Melanoma } \\
\text { differentiation antigens }\end{array}$} & \multicolumn{2}{l}{ Cancer/testis antigens } \\
\hline & gp100 & tyrosinase & MART-1 & MAGE-A3 & NY-ESO \\
MZ2 & - & - & - & ++ & - \\
D10 & + & + & ++ & ++ & - \\
Me39 & - & - & ++ & ++ & - \\
WM115 & - & - & + & ++ & - \\
RE & - & - & - & ++ & - \\
Me59 & - & - & - & $+/-$ & - \\
Me67 & - & - & - & ++ & - \\
Na8 & - & - & - & - & - \\
HBL & + & + & ++ & ++ & - \\
\hline
\end{tabular}

*MAA = melanoma-associated antigens; Expression levels were assessed using conventional PCR and evaluated semiquantitatively by densitometry. gp $\mathbf{1 0 0}=$ melanosomal matrix protein gp100; tyrosinase = key enzyme in melanin biosynthesis; MART-1 = Melan-A/MART-1 = melanoma antigen recognized by $\mathrm{T}$ cells; MAGE-A3 = melanoma antigen-A3 family, NY-ESO = cancer/testis antigen (see text); $(+)=$ moderate expression; $(++)=$ strong expression; $(-)=$ no expression detectable.

\section{CD133 expression is detectable in metastatic melanoma} cell lines

Our data indicate that melanoma cell lines express discrete stem cell markers. However, the distribution of the expression was highly variable among the cell lines under investigation (Table 3). CD133 expressing could be detected in 5/9 melanoma cell lines including D10, Me39, RE, Me59, and Na8, decreasing from $80-1 \%$ of positive CD133+ subsets. Over $80 \%$ of D10 cells expressed CD133 (Figure 1A). In addition, nearly $2 \%$ of the Me39 cells (Figure 1B), more than 3\% of RE cells (Figure 1C), and more than $1 \%$ of $\mathrm{Na} 8$ (Figure 1D) and Me59 (Figure 1E) cells also expressed CD133. Strikingly, CD105, the TGF- $\beta$ receptor, was detectable on more than $75 \%$ of the cells of all melanoma cell lines under

Table 2 Expression of regulatory core transcription factors in melanoma cell lines

\begin{tabular}{llll}
\hline Cell line & NANOG & OCT4 & SOX2 \\
\hline MZ2 & - & - & - \\
D10 & ++ & + & - \\
Me39 & ++ & ++ & - \\
WM115 & + & + & + \\
RE & ++ & ++ & - \\
Me59 & - & + & - \\
Me67 & + & - & - \\
Na8 & - & - & - \\
HBL & + & - & - \\
\hline
\end{tabular}

NANOG = Nanog homeobox; OCT4 = POU-domain transcription factor; SOX2 = SRY (sex determining region Y)-box2; $(-)=$ no expression $\left(<10^{-3}\right) ;(+)=$ moderate expression $\left(\geq 10^{-3}<10^{-2}\right) ;(++)=$ strong expression $\left(\geq 10^{-2}\right)$. Expression level of TF gene reported as $2^{-\mathrm{Ct}}$, where $\mathrm{Ct}=(\mathrm{Ct}$ [TF gene] - $\mathrm{Ct}$ [ACTB]) sample.
Table 3 Phenotypical characterization of melanoma cell lines

\begin{tabular}{llllll}
\hline Cell line & CD133 & CD105 & CD146 & CD271 & CD117 \\
\hline MZ2 & neg. & 86.41 & 73.92 & 99.74 & neg. \\
D10 & 89.66 & 77.14 & 98.79 & neg. & neg. \\
Me39 & 1.88 & 95.65 & 100.00 & 7.40 & neg. \\
WM115 & neg. & 87.60 & 99.6 & 45.24 & neg. \\
RE & 3.11 & 74.84 & 98.31 & 59.96 & 1.28 \\
Me59 & 1.00 & 75.55 & 36.40 & 2.72 & 18.95 \\
Me67 & neg. & 75.94 & 73.76 & 10.75 & neg. \\
Na8 & 1.05 & 97.22 & 0.67 & 82.54 & neg. \\
HBL & neg. & 22.66 & 30.08 & 2.32 & 99.46 \\
\hline
\end{tabular}

Expression levels of fluorochrome-conjugated monoclonal antibodies against surface markers of interest on melanoma cell lines. Frequency and distribution of cells carrying surface markers expressed as percentages of positive gated cells; "neg." indicates percentages of positive gated cells $<1 \%$.

investigation with the exception of HBL. Na8 and HBL showed peculiar patterns of CD105, CD271, and CD117 expression. Virtually $83 \%$ of $\mathrm{Na} 8$ cells bound antiCD271 antibody as opposed to $2 \%$ of HBL cells. In stark contrast, CD117 (c-kit) expression levels displayed an opposite pattern with less than $1 \%$ positivity in $\mathrm{Na} 8$ cells and more than $99 \%$ in HBL. In general, HBL emerged as an outstanding cell line in our panel since virtually all cells expressed CD117 with relatively high intensities (Figure 1F). No other surface marker under investigation was found to be expressed in these cells under these conditions. WM115 was previously reported to contain a CD133+ subpopulation [20]. This could not be confirmed in our experiments. Nonetheless, 2 subpopulations were identified in WM115. One fraction stained positive for CD105 (88\%) and another one for CD271 (45\%). The corresponding mean fluorescence intensities (MFI values) are attached as additional file (see Additional file 1).

\section{D10, Na8 and HBL cells grow in spheroids}

Evidence of the capacity of CSCs to grow in spheroid structures has been repeatedly reported (refer to Introduction and Materials and Methods). To assess these features in the melanoma cell lines under investigation, cell lines were cultured in flasks pretreated with poly-HEMA, preventing attachment to the plastic surface. In these conditions, the D10 cell line - as well as the Na8 and HBL cell line - were clearly generating spheroids (Figure 2A-C). Furthermore, the phenotypes of these 3 cell lines were assessed upon 3D culture. Cells were labeled again with mAbs against CD133, CD117, CD105, CD271, and CD146; the results were compared with the staining observed in cells cultured in 2D (Table 3). Interestingly, the only modification observed in $3 \mathrm{D}$ as compared to the $2 \mathrm{D}$ cultures was represented by a modest increase of the fraction of CD133+ cells in the Na8 cell line (Figure 3). In contrast, expression levels of CD105, 

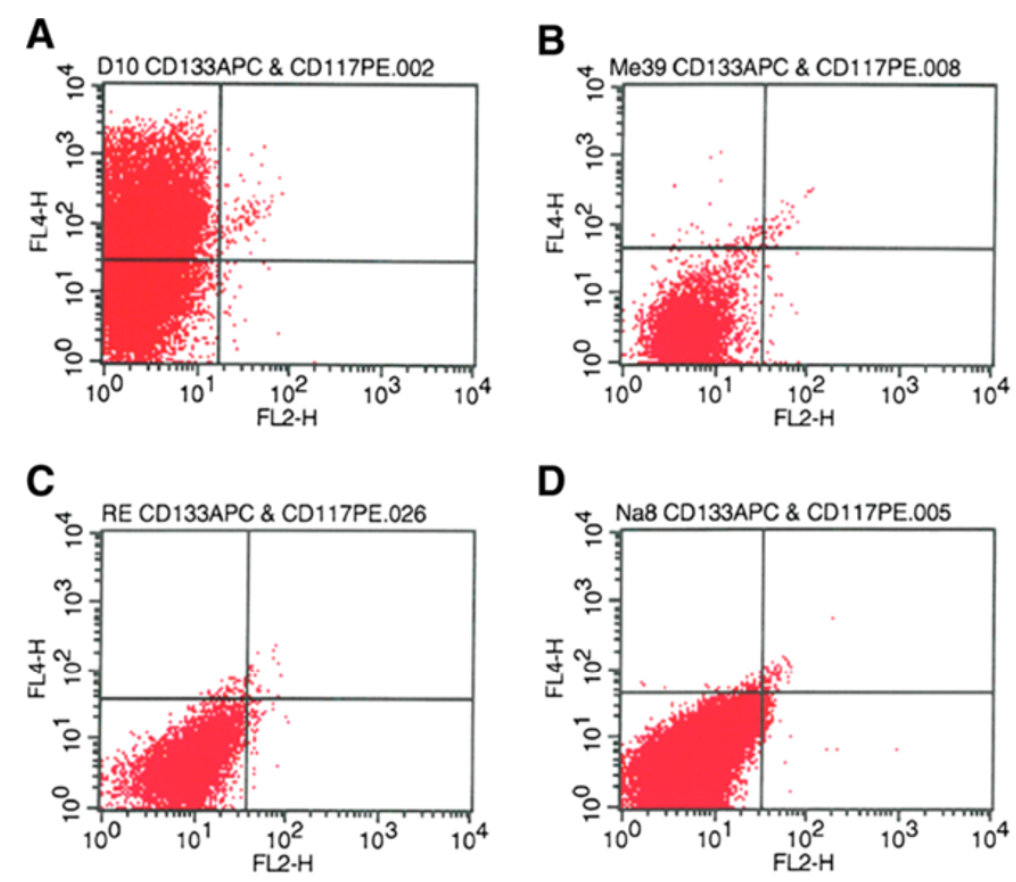

D
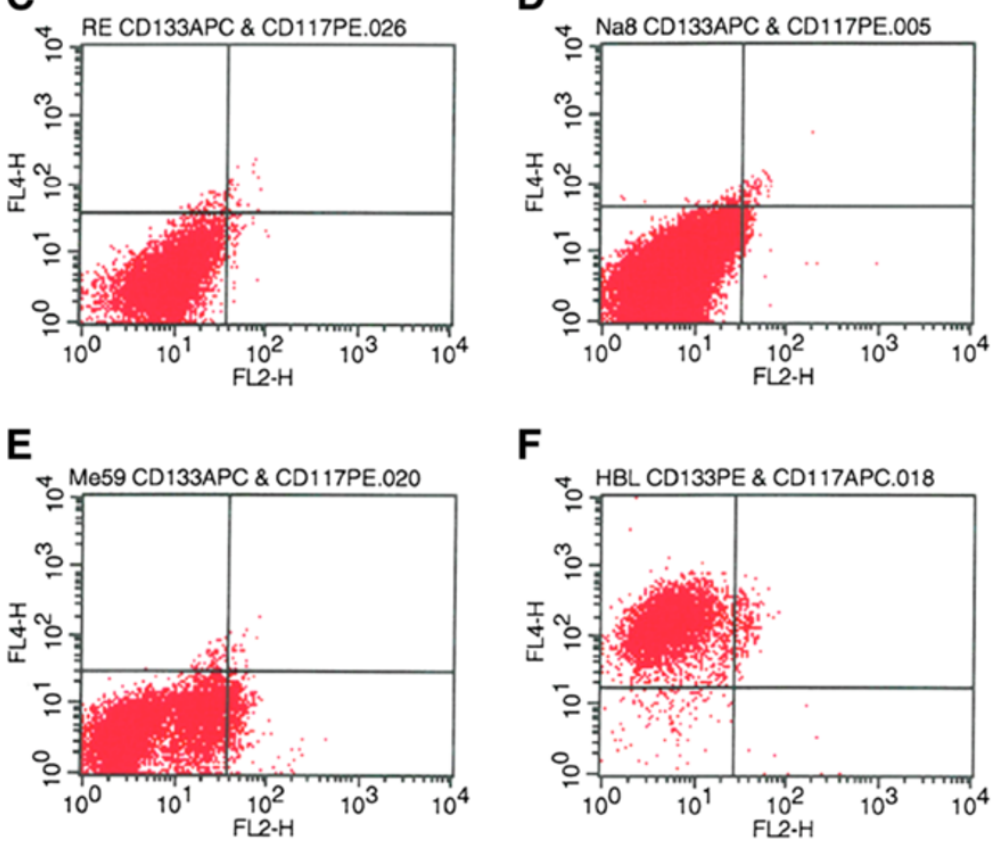

$\mathbf{F}$

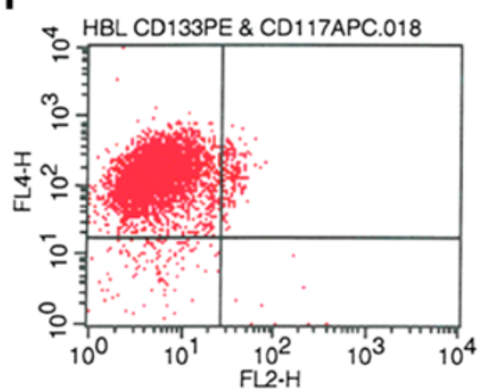

Figure 1 Expression of CD133 and CD117 in melanoma cell lines. Cell lines were stained with APC-and PE-conjugated monoclonal antibodies against the CD133 and CD117 epitope. The figure shows the dotplots of A: D10, B: Me39, C: RE, D: Na8, E: Me59 and F: HBL. Corresponding statistics are shown in Table 3.

CD117, CD146, and CD271 were unmodified (data omitted for simplicity).

\section{CD133 expression in D10 cells correlates with clonogenicity}

Clonogenic assays were performed by limiting dilution analysis (LDA) on cells magnetically sorted according to their expression of selected markers (Figure 4A). The frequency of proliferating cells was evaluated by Poisson's distribution. Poisson's distribution yielded that $40.60 \% \pm 2.63$ of the CD133+ cells were capable of giving rise to cell colonies, as opposed to $6.15 \% \pm 0.598$ of the negative fraction (Figure 4B). CD133+ D10 cells have a statistically significant higher clonogenic capacity as compared to CD133- D10 cells ( $\mathrm{p} \leq 0.001)$. Taken together, the expression of CD105 was not associated with a significantly higher clonogenic capacity in the cell lines investigated. In contrast, the CD105- fraction in Me39,
WM115, Na8, and HBL cell lines even dominated in terms of clonogenic capacity, but not significantly. Except for the RE cell line where all CD271- cells were capable of forming colonies, CD271+ and CD271- cells possessed equal clonogenic potential. CD117 was expressed on almost all HBL cells. Notably, the absence of CD117 expression was not compatible with the in vitro survival of those cells. Referring to Poisson's distribution, almost all HBL cells expressing CD117 are capable of inducing colony growth.

\section{CD133+ D10 cells induce tumor growth in vivo}

D10 cells were chosen from the panel of melanoma cell lines since they frequently expressed CD133 with a significantly higher clonogenic capacity and for their ability to grow in spheroids. In vivo tumor formation and growth could be observed with CD133+ D10 cells and 

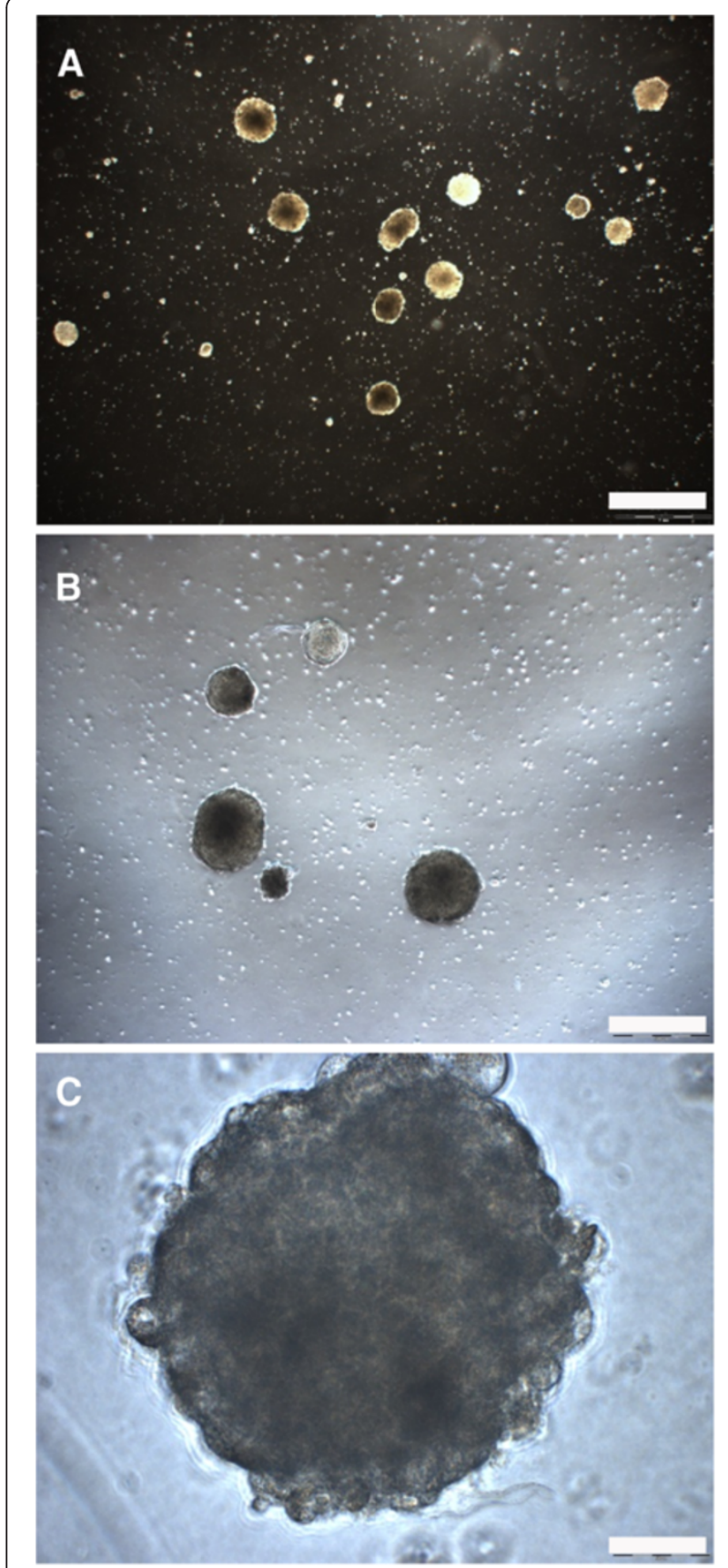

Figure 2 Na8 spheroids in poly-HEMA-coated tissue culture flasks. A: $2 \times$ magnification (scale bar $1 \mathrm{~mm}$ ). B: $4 \times$ magnification (scale bar $500 \mu \mathrm{m}$ ). C: 40× magnification (scale bar $50 \mu \mathrm{m}$ ).

unsorted D10 cells. CD133- D10 failed to induce tumor growth. Furthermore, isolated CD133+ D10 cells showed an accelerated growth compared to unsorted D10 cells (Figure 5). Xenografts induced by CD133+ D10 cells strongly stained positive for CD133 as shown by immunohistochemistry (Figure 6D). In contrast, CD133 expression in xenografts induced by unsorted D10 cells was less intense (Figure 6C). Additionally, CD133 expression was also detected in sections of a primary human melanoma (Figure 6B) and a lymph node metastasis (Figure 6E) but hardly in normal skin sections (Figure 6A).

\section{MGP expression is upregulated in CD133+ D10 cells}

Following chip data processing and statistical analysis using Fisher's ANOVA, 68 up- and 46 downregulated genes in CD133+ as compared to CD133- D10 cells (+/-1.3-fold, $\mathrm{p} \leq 0.001)$ were obtained. The list of all differentially expressed genes is provided as additional file (Additional files 2 and 3). Two genes were outstandingly upregulated, i.e., matrix GIa protein (MGP) and prominin 1 (PROM1, CD133). The expression of MGP in CD133+ D10 cells and the fold of change of expression in relation to CD133- cells could be confirmed by PCR (see Additional file 4). A number of other genes upregulated in CD133+ D10 cells encode proteins involved in cell proliferation, including insulin-like growth factor-1 (IGF-1) and its binding protein insulin-like growth factor-binding protein-3 (IGFBP-3). Downregulated genes included those encoding tenascin $C$ and TIMP1. Interestingly, the expression of $B C L 2 A 1$, a gene that encodes a member of the pro- and antiapoptotic BCL-2 protein family, was downregulated.

\section{Categorization of differentially expressed genes}

Differentially expressed genes were categorized by their molecular function (Figure 7A) and the biological processes (Figure 7B) that they are involved in by using the PANTHER classification system. Three of the 68 upregulated genes (HJURP, LL22NCO3-75B3.6, and $D C C 1$ ) and 2 of the 46 downregulated genes (GOM1 and CINP) could not be identified by PANTHER. All differentially expressed genes and their symbols are provided as additional files.

\section{Discussion}

This study aimed at investigating whether established melanoma cell lines contain tumor cell subsets that can be referred to as CSCs. Since CD133+ melanoma cells are rare in clinical samples and difficult to isolate from surgical specimens, the expression of stem cell surface markers, in particular CD133, was analyzed in 9 wellestablished human melanoma cell lines, each and every one originally derived from human metastatic malignant melanoma. The selection of melanoma cell lines reflects the heterogeneity of the original tumors and includes highly differentiated cell lines (D10, WM115, HBL) expressing the melanoma differentiation antigens gp100, tyrosinase, and MART-1, and undifferentiated cell lines. The melanoma cell line named WM115 was included in the study because of its previous characterization by Monzani's group in 2007 [20] including a CD133+ 

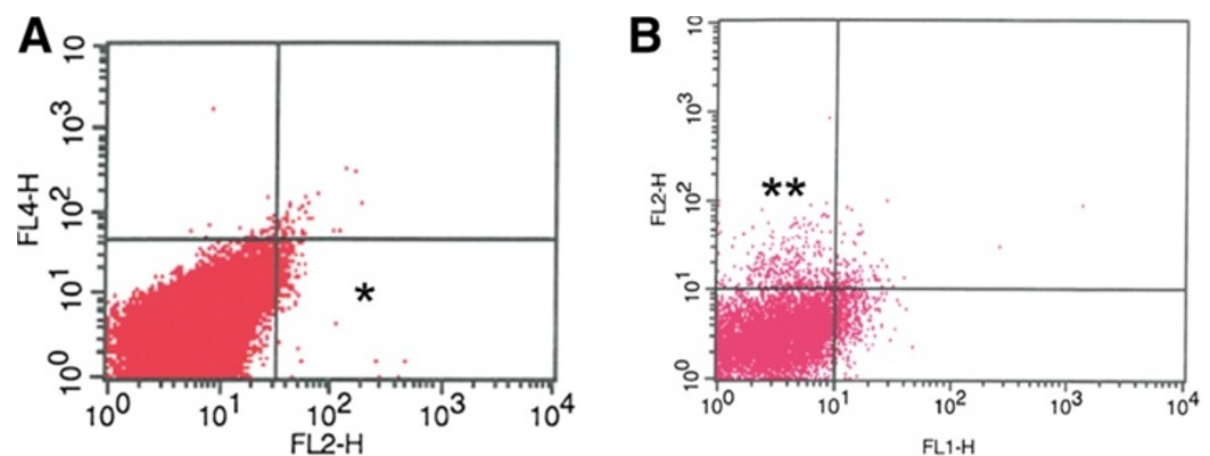

Figure 3 CD133 expression in Na8 cells after 2D and 3D culture. Dotplots of CD133-Expression (PE-conjugated) after A: monolayer culture, B: 3D culture (spheroidal growth). Following 3D- culture in pre-treated tissue culture flasks, almost 5\% of the Na8 cells stained positive for CD133 compared to $1 \%$.
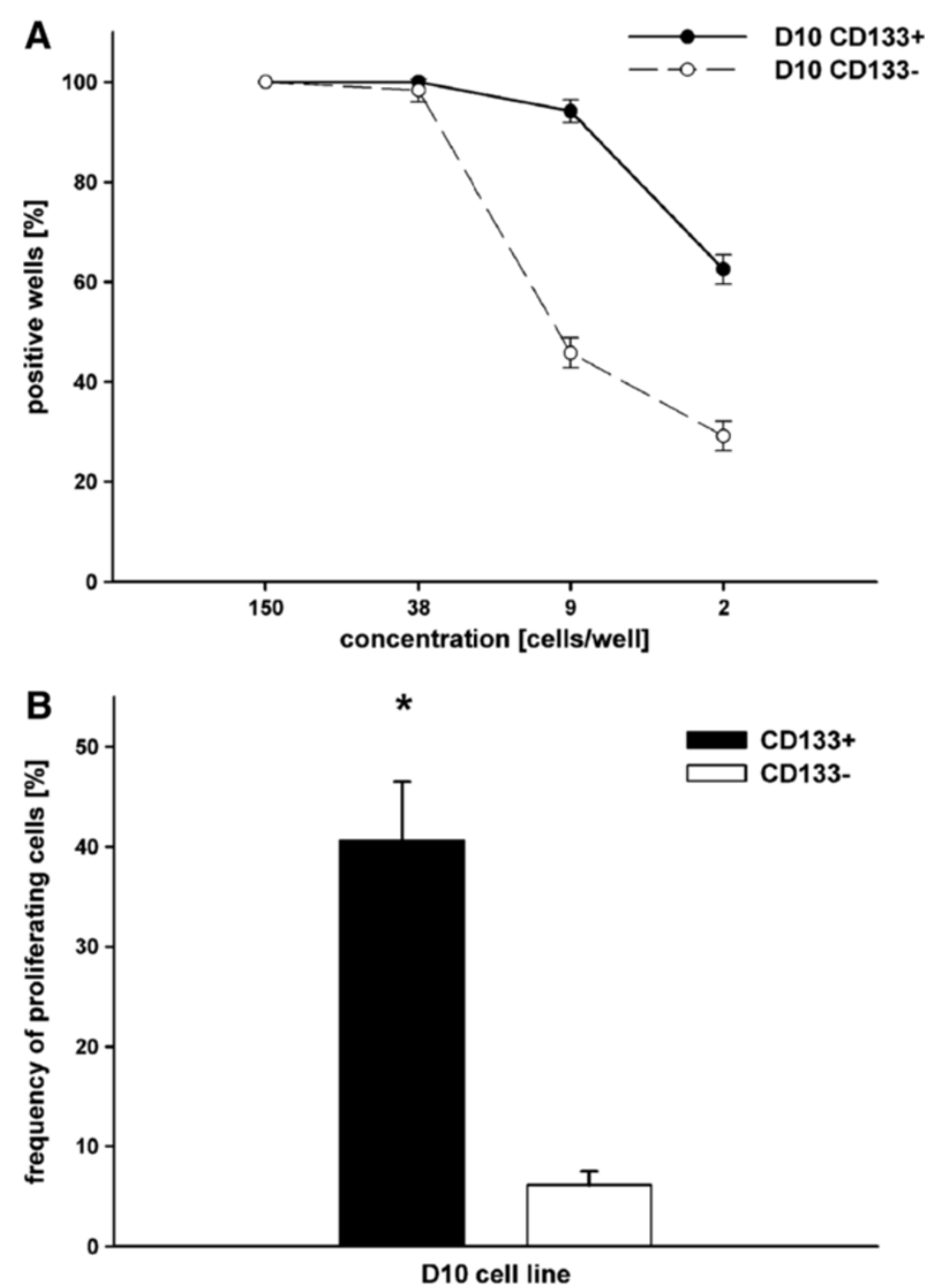

Figure 4 Limiting dilution analysis and clonogenic assay. A: Limiting dilution analysis. Percentage of positive wells (positive well = 1 cell colony/well) at different cell concentrations of CD133+ and CD133- D10 cells for calculating Poisson's distribution (Figure 4B). B: Clonogenic capacity of D10 cells. Results of Poisson's distribution with the frequency of proliferating cells in CD133+ (black column) and CD133- (white column) D10 cells, results expressed as mean percentages \pm SD; $\left(^{*}\right)=p \leq 0.001$. 


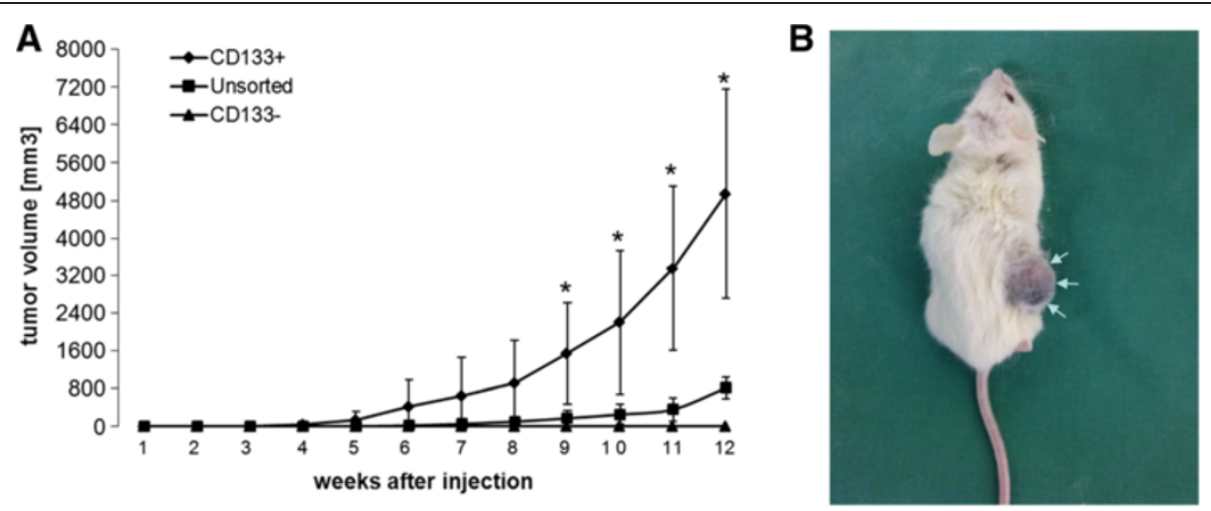

Figure 5 Tumorigenicity of D10 cells. A: The Change in tumor volume over a period of 12 weeks is shown in the graph. $(*)=p \leq 0.05$. Bars represent SD. Tumor progression of CD133+ D10 cells significantly $(p \leq 0.05)$ differs from unsorted D10 tumors. B: Injection of CD133+ D10 cells into the right flank (R) leads to tumor formation (white arrows) while CD133- D10 cells are not capable of inducing tumor growth. Bilateral injection of unsorted D10 cells is followed by bilateral tumor formation.

phenotype and a strong tumorigenic potential [21]. For further characterization of our cell lines, the expression of the regulatory core transcription factors NANOG, SOX2, and OCT4 was analyzed. Those genes form a regulatory core essential for maintenance of the undifferentiated state of stem cells and the process of stem cell self-renewal in a complex regulatory network [22-24]. Interestingly, high NANOG expression was detectable on the rather differentiated cell lines D10, WM115, and HBL, suggesting that either these cell lines have been misclassified previously or
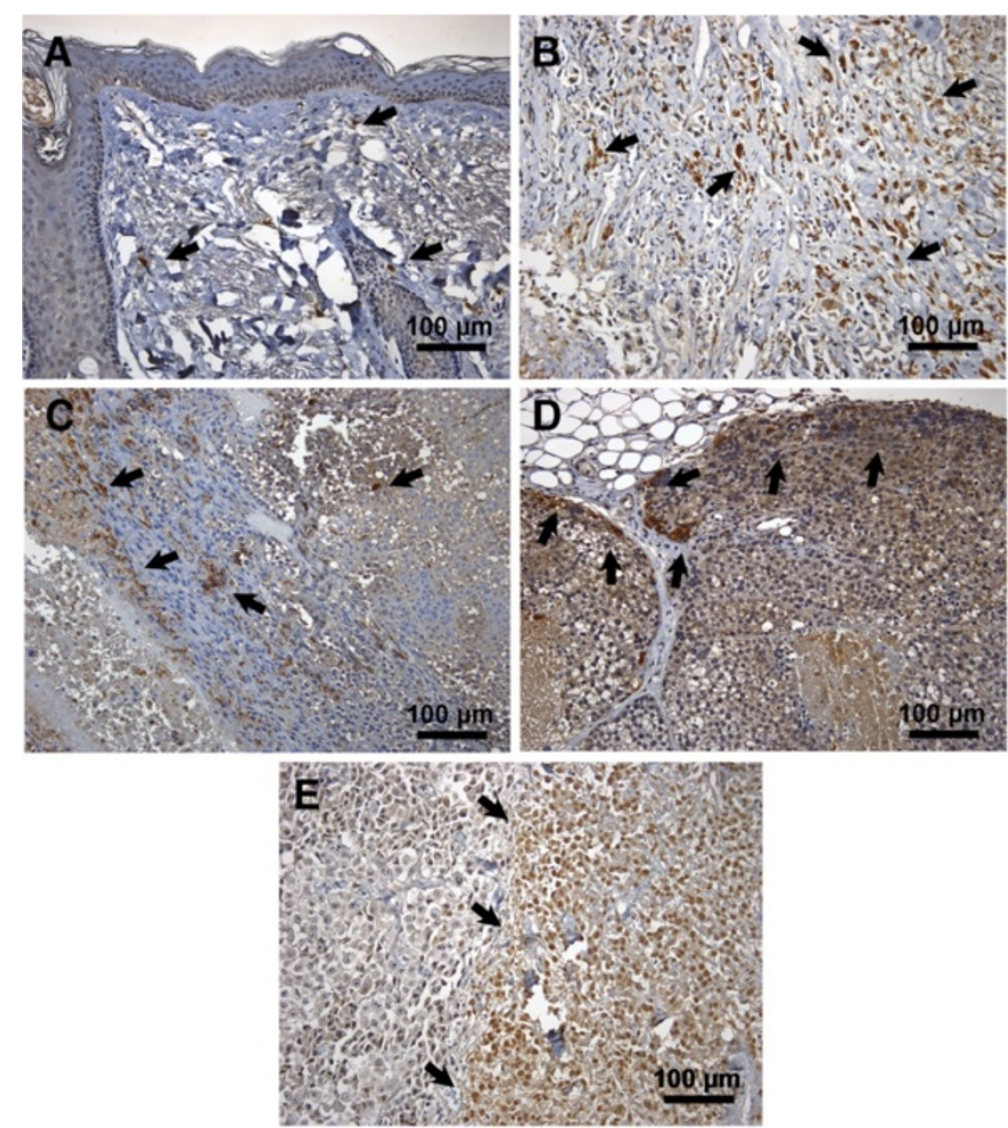

Figure 6 Immunohistochemistry of xenografts and patient samples. CD133 expression (brown spots, black arrows) in different tissue samples: A: normal skin section showing a few brown spots. B: primary melanoma tissue section, $\mathbf{C}$ : melanoma lymph node metastasis and $\mathbf{D}$ : xenograft induced by CD133+ D10 cells, all showing intense positivity for CD133. E: xenograft induced by unsorted D10 cells with less intense CD133+ staining. Scale bar $100 \mu$ m. 

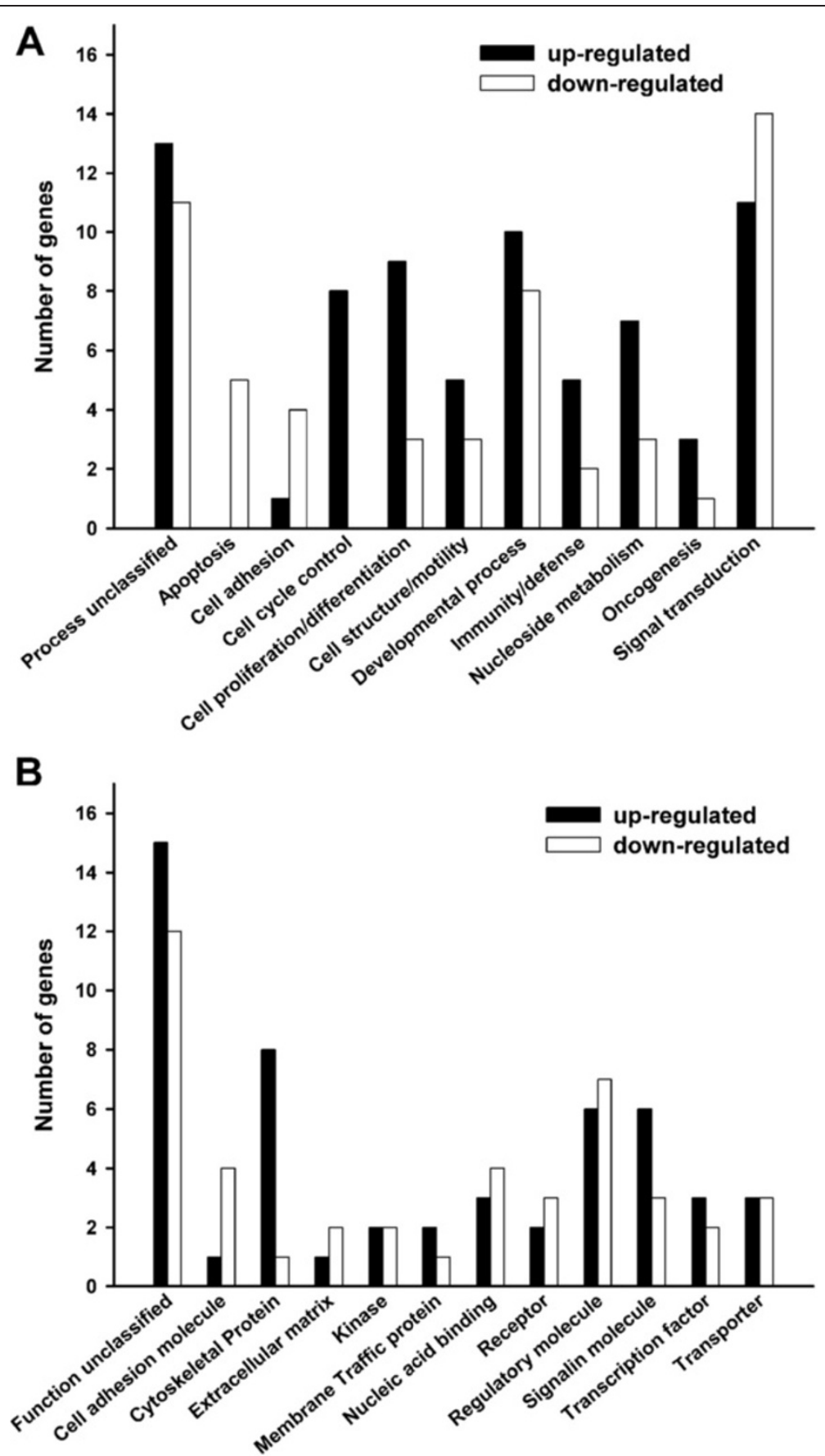

Figure 7 Categorization of differentially expressed genes, detected in CD133+ D10 cells. Number of genes encompassed with a specific A: molecular function and B: biological process. Black columns: upregulated genes. Gray columns: downregulated genes.

the overexpression of NANOG might not be obviously linked to the state of differentiation of individual melanoma cell lines. Further studies are necessary to uncover the role of these transcription factors in melanoma cell lines.

Melanoma cell lines do express stem cell associated surface markers; however, their distribution was highly variable. Surprisingly, the expression of CD133 on
WM115 cells was not detectable under the conditions used in this study. In contrast with the general thinking that CD133+ CSCs may represent only a minimal part of the total tumor cell population, CD133 was expressed on high percentages of D10 cells and very small percentages of Me39, RE, Me59, and Na8 cells. CD117 was expressed on virtually all HBL cells indicating that this might represent a specific feature of this highly 
differentiated cell line. Functional analysis of the surface markers used in this study revealed that only CD133+ D10 cells constantly demonstrated a significantly higher clonogenic capacity as compared to the CD133- fraction. The clonogenic capacity of the other markers (CD105, CD146, and CD117) throughout the cell lines was highly variable or oppositional in the samples examined. In a recent publication, CD271+ melanoma stem cells were found to be associated with metastasis, heterogeneity, and long-term growth [25]. In our panel, CD271+ cells could be identified in all cell lines except for D10. However, CD271+ cells did not demonstrate a significantly higher clonogenic capacity as compared to their negative counterparts.

Since the expression of CD133 was associated with a significantly higher clonogenic capacity in D10 cells the tumorigenic potential of this subset was investigated in vivo. CD133+ and unsorted D10 cells induced tumor formation in vivo. Shown by immunohistochemistry, xenografts induced by CD133+ D10 cells stained positive for CD133, confirming the conservation of this marker during tumor formation. The results of our study in which the tumorigenic potential of a CD133+ subset is demonstrated contrary to the CD133- fraction coincides with the classical cancer stem cell hypothesis and most articles published in this area. However, according to recent publications, the CD133- subset is also capable of conversely inducing tumor growth upon transplantation. Furthermore, during a suggested metastatic transition, originally CD133- induced tumors can transform to CD133+ xenografts. Two explanations of this phenomenon have been suggested so far: (1) the process of tumor initiation is a developmental process in which the CD133- subset gains tumorigenic capacity in the host, most likely through the influence of the adjacent environment or niche [26,27]. (2) CD133 expression does not identify the entire population of tumor-initiating cells [28]. In this context, future investigations on these particular CD133 subsets of D10 cells might help to both, uncover the role of the tumor niche during tumorigenesis and to help to explain the phenomenon of marker transformation in vivo.

Based on these results, gene expression profiling using gene chips was performed on CD133+ and CD133- D10 cells. MGP (32.4-fold) and positive control PROM1 (CD133; 27.7-fold), were outstandingly upregulated across the other 68 upregulated genes. In addition, IGF1 and its major corresponding binding protein IGFBP-3 were, respectively, 3.5 and 2.7-fold upregulated in CD133+ D10 cells as compared to the CD133- fraction. IGF-1 plays a key role in the development and growth of multiple tumors and in the prevention of apoptosis. In melanoma cells, IGF-1 has been shown to mediate resistance to anoikis, a form of programmed cell death, which is induced by anchorage-dependent cells detaching from the surrounding extracellular matrix. Recently, Hilmi and co-workers [29] also demonstrated that IGF-1 promotes resistance to apoptosis in melanoma cells through an increased expression of BCL2, BCL-X (L), and survivin. Inconsistently with findings published by Fang's group [14], CD133+ D10 cells had not upregulated the expression of ABCG2 (ATP-binding cassette, sub-family G (WHITE), member 2A), which was identified to be overexpressed in primary or metastatic melanoma compared to benign melanocytic nevi [18].

\section{Conclusions}

Taken together, our data suggest that established melanoma cell lines represent useful tools for the investigation of functional features of CSCs. In particular, the CD133+ subset of D10 cell line with a significantly higher clonogenic and tumorigenic capacity might qualify as melanoma cancer stem cell model. However, since the CD133- subset failed to induce xenografts the role of the tumor niche for this particular subset needs to be evaluated in future studies. Furthermore, gene profiling of the CD133+ subset of the D10 melanoma cell line has resulted in the identification of 1 gene, i.e., MGP, consistently upregulated, in comparison with the CD133subset of the same cell line. Further in vitro and in vivo studies are warranted to validate these results at the gene and protein level and to assess the potential diagnostic and prognostic relevance of MGP, CD133, and IGF expression in clinical melanoma specimens.

\section{Methods}

\section{Cell culture}

A panel of melanoma cell lines representative of tumors at diverse differentiation stages was selected. All cell lines were derived originally from metastatic melanomas. The WM115 cell line was obtained from the ATCC; MZ2 cell line was a gift from Dr. van der Bruggen (Brussels, Belgium), whereas HBL, Na8, and D10 were provided by Dr. Eberle (Basel, Switzerland). RE, Me39, Me59, and Me67 cell lines were generated by Giulio Spagnoli's group (Basel, Switzerland). Cell lines were cultured in Gibco ${ }^{\circ}$ DMEM (Invitrogen AG, Basel, Switzerland; containing $4.5 \mathrm{~g} / \mathrm{L}$ glucose and NEAA), supplemented with 10\% FBS (Invitrogen AG, Basel, Switzerland), 1\% sodium pyruvate (Invitrogen AG, Basel, Switzerland), 1\% HEPES buffer (Invitrogen AG, Basel, Switzerland), and 2\% PSG (Invitrogen AG, Basel, Switzerland). For investigating 3dimensional (3D) spheroidal growth, tissue culture flasks (75 $\mathrm{cm}^{2}$, tissue culture flasks) (TPP, MIDSCI, St. Louis, MO, USA) were pretreated with poly-HEMA (SigmaAldrich $^{\oplus}$, St. Louis, MO, USA) according to the manufacturer's instructions. Cell lines were also cultured in both $20 \%$ and $1 \%$ oxygen humidified atmosphere at $37^{\circ} \mathrm{C}$. 


\section{Fluorescent-activated cell sorting (FACS)}

Cell suspensions from melanoma cell lines were incubated with the following fluorochrome-conjugated antibodies: PE/APC-CD133, FITC-CD105, APC-CD271, FITC-CD146 , and APC-CD117 (Becton-Dickinson, San José, CA, USA). Between $5 \times 10^{5}$ and $5 \times 10^{6}$ cells per tube were labeled with $5 \mu \mathrm{L}$ of labeled monoclonal antibodies (mAbs) of interest. Cells were fixed by in $1 \%$ paraformaldehyde (PAF). The phenotype was assessed using a FACSCalibur ${ }^{\circ}$ flow cytometer (Becton-Dickinson).

\section{Limiting dilution and clonogenic assay}

In order to assess the possible differences in the clonogenic capacity of cells carrying selected surface markers, melanoma cell lines were incubated with MicroBeads ${ }^{\circ}$ loaded with CD105, CD133, CD271, and CD117 (Miltenyi Biotec, Bergisch Gladbach, Germany) and applied to columns allowing their magnetic separation into positively and negatively labeled fractions by using a MiniMACS ${ }^{\text {ma }}$ separation unit (Miltenyi Biotec, Bergisch Gladbach, Germany) according to established protocols. In this study, cell suspensions of melanoma cell lines were diluted serially. Cell counts were carried out after 14 days. In this study, positive results (positive wells) were determined as at least 1 cell colony per well. The frequency of proliferating cells for each target phenotype was assessed by applying Poisson's distribution [30]. Frequency of proliferating cells was expressed as mean \pm SD. Differences between groups were assessed by one-way analysis of variance (ANOVA), and differences within each group were analyzed by one-way repeated-measures ANOVA. To isolate overall differences, appropriate differences were considered significant at $\mathrm{p} \leq 0.001$.

\section{Animal experiments and immunohistochemistry}

All animal experiments were carried out under anaesthesia by intraperitoneal injections of $0.1 \mathrm{~mL}$ saline solution (Sigma, Steinheim, Germany) per $10 \mathrm{~g}$ body weight containing $90 \mathrm{mg} / \mathrm{kg}$ body weight ketamine hydrochloride (KetavetVR ; Parke Davis, Freiburg, Germany) and $25 \mathrm{mg} / \mathrm{kg}$ body weight dihydroxylidinothiazine hydrochloride (RompunVR; Bayer, Leverkusen, Germany). Conduction of the experiments was approved by the institutional ethical committee and the Federal Office for Consumer Protection and Food Safety with the reference number 33.9-42502-04-11/0401. Magnetically sorted $1 \times 10^{6} \mathrm{CD} 133+\mathrm{D} 10$ cells (MicroBeads ${ }^{\circ}$, Miltenyi Biotec, Bergisch Gladbach, Germany) were subcutaneously injected into the right flank regions of female NOD scid gamma mice (NSG; NOD.Cg-Prkdcscid Il2rgtm1Wjl/ SzJ) and $1 \times 10^{6}$ CD133- D10 cells in the contralateral region. Unsorted D10 cells $\left(1 \times 10^{6}\right.$ cells respectively) were bilaterally injected as control group. Eight mice were assigned to each group. Tumor growth was assessed once a week using a caliper and the actual tumor mass was estimated by calculating the volume according to the ellipsoid volume formula: $4 / 3 \pi(1 / 2 \times$ lenght $\times$ width $\times$ height). Statistical analysis was carried out using ANOVA. Mice were euthanized after 12 weeks or in case of fulminate tumor growth. Xenografts were harvested for immunohistochemistry. For detection of CD133 formalin-fixed specimens were embedded in paraffin and cut into five- $\mu \mathrm{m}$-thick sections. The sections were incubated with a rabbit anti-human PROM1/CD133 antibody (Abnova, Taipei, Taiwan). A biotin-conjugated goat antirabbit antibody (Dianova, Hamburg, Germany) was used as secondary antibody. Incubation with streptavidinhorseradish peroxidase (Dianova) was followed by color development with 3, 3'-diaminobenzidine (DAB) substrate (Vector Laboratories, Burlingame, USA) at room temperature. The sections were counterstained with hemalaun (Merck KGaA, Darmstadt, Germany) and examined by light microscopy (DM4000B, Leica, Wetzlar, Germany). For negative control the primary antibody was omitted. All control stainings were negative.

\section{Gene expression}

The expression of the genes encoding the melanomaassociated antigens (MAAs) gp100, tyrosinase, and Melan-A/MART-1 and the cancer/testis antigens (CTA) MAGE-A3 and NY-ESO was assessed by conventional PCR, its extent was semiquantitatively evaluated by densitometry as previously described by Spagnoli [31,32]. Primers and probes for the housekeeping gene $B$-actin (hACTB) as well as for NANOG, OCT4, SOX2, and MAGE-3 and MGP were provided by Assays-on-Demand, Gene Expression Products (Applied Biosystems, Foster City, CA, USA). The other primer sequences (gp100, tyrosinase, Melan-A/MART-1, and NY-ESO) were derived from existing literature, as indicated below or were generated using appropriate software (Primer Express ${ }^{\mathrm{Tm}}$, Applied Biosystems, Foster City, CA). Sequences of primers and probes and Assays-on-Demand are attached as additional files (see Additional files 5 and 6). TaqMan ${ }^{\circ}$ analysis was carried out on a 7900HT Sequence Detection System. Singleplex PCR reactions were performed in Fast Gene Quantification in 96-Well Plates (the thermal cycling conditions included a step of $20 \mathrm{~s}$ at $95^{\circ} \mathrm{C}$ followed by 40 cycles of $95^{\circ} \mathrm{C}$ for $1 \mathrm{~s}$ and $60^{\circ} \mathrm{C}$ for $20 \mathrm{~s}$ ) with The TaqMan Fast Universal PCR Master Mix $(10 \mu \mathrm{l})$ in a volume of $20 \mu \mathrm{l}$ containing $2 \mu \mathrm{l}$ of cDNA and $1 \mu \mathrm{l}$ of specific TaqMan ${ }^{\circ}$ Gene Expression Assay. All reactions were performed in triplicate. All reagents were from Applied Biosystems (Foster City, CA, USA). The comparative Ct method by Pfaffl [33] was employed to determine the MGP expression in CD133+ and CD133- D10 cells. The MGP expression in CD133D10 cells was identified as a calibrator sample and the 
CD133+ sample expressed $n$-fold mRNA relative to the calibrator. Final amounts of target were determined as follows: target amount $=2^{-\mathrm{Ct}}$, where $\mathrm{C}_{t}=\left[\mathrm{C}_{t}\right.$ (MGP D10 CD133+) - $\left.\mathrm{C}_{\mathrm{t}}(\mathrm{ACTB})\right]_{\text {sample }}-\left[\mathrm{C}_{\mathrm{t}}(\mathrm{MGP}\right.$ D10 CD133-) $\left.\mathrm{C}_{\mathrm{t}}(\mathrm{ACTB})\right]_{\text {calibrator }}$.

\section{Cell sorting for microarray studies}

CD133+ and CD133- D10 cells were sorted using a FACSVantage ${ }^{\oplus}$ Cell Sorter for genome-wide gene expression profiling. About $40 \times 10^{6}$ D10 cells were isolated and resuspended in $25 \mu \mathrm{L}$ PBS containing 2\% FBS for $1 \times 10^{6}$ cells. Afterwards, D10 cells were labeled with $2.5 \mu \mathrm{L}$ fluorochrome-linked mAbs against CD133 (CD133/2PE; Miltenyi Biotech, Bergisch Gladbach, Germany) for $1 \times 10^{6}$ cells. D10 cells were resuspended in $5 \mathrm{~mL}$ polyethylene tubes (BD Falcon ${ }^{\mathrm{mm}}$, BD Biosciences, San Jose, CA, USA) at a concentration of $10^{7}$ cells $/ \mathrm{mL}$ in a sorting solution. To avoid cells from sticking to the tube's inner surface, $5 \mathrm{~mL}$ polyethylene tubes were coated with $1 \%$ BSA; in order to maintain single cell suspension and prevent cell clumping, the sorting solution based on PBS, contained $0.5 \%$ BSA and $5 \mathrm{mM}$ EDTA. CD133+ and CD133- D10 cells were sorted out in duplicate by the FACSVantage ${ }^{\oplus}$ cell sorter until $10^{6}$ cells of each condition were collected in the DMEM in uncoated polyethylene $5 \mathrm{~mL}$ tubes (BD, Falcon). The results of the cell sorting are attached as additional file (see Additional file 7).

\section{Microarray studies}

Genome-wide gene expression profiling was carried out according to MIAME-standards (Minimal Information about an Array Experiment) using Affymetrix GeneChips ${ }^{\circ}$ Human Genome U133A 2.0 expression arrays (Affymetrix, UK Ltd.). The experimental design and related protocols are published in a MIAME-compliant format and can be reviewed on ArrayExpress ${ }^{\circ}$ (Accession Number: E-MEXP3542). Briefly, total RNA was isolated from previously sorted CD133+ and CD133- D10 cells by using an RNeasy Mini Kit (Qiagen, Basel, Switzerland) following manufacturer's protocols. After elution, a total RNA cleanup was performed using an RNeasy MinElute ${ }^{\oplus}$ Cleanup Kit (Cat \# 74204). The RNA yield was quantified by spectrophotometric analysis (NanoDrop ${ }^{\circ}$ Technologies, Wilmington, USA) using the convention that 1 absorbance unit at $260 \mathrm{~nm}$ equals to $40 \mu \mathrm{g} / \mathrm{mL}$ RNA. Aliquots of each RNA sample were saved for RNA fragment analysis in an Agilent Bioanalyzer $2100^{\circ}$ (Agilent Technologies, Basel, Switzerland) by using an RNA 6000 Nano Kit (Agilent Technologies, Basel, Switzerland).

\section{Target synthesis}

Biotin-labeling of RNA was performed as described in the GeneChip ${ }^{\oplus}$ Expression Analysis Technical Manual (Affymetrix, Santa Clara, USA). Double-stranded cDNA was synthesized according to the One-Cycle cDNA Synthesis Kit (Affymetrix, Cat \# 900431), starting from $5 \mu \mathrm{g}$ of the total RNA. The material was purified with a Sample Cleanup Module (Affymetrix, Cat \# 900371). Purified cDNA was used for an in vitro transcription reaction by using an IVT labeling kit (Affymetrix, Cat \# 900449). The hybridization cocktail $(130 \mu \mathrm{L})$ containing fragmented biotin-labeled target cRNA at a final concentration of $0.05 \mu \mathrm{g} / \mu \mathrm{L}$ was transferred into an Affymetrix Human Genome U133A 2.0 and incubated at $45^{\circ} \mathrm{C}$ on a rotator in a hybridization oven 640 (Affymetrix) for $16 \mathrm{~h}$ at $60 \mathrm{rpm}$. The arrays were washed and stained on a Fluidics Station 450 (Affymetrix) by using a Hybridization Wash and Stain Kit (Affymetrix, Cat \# 900720). In order to increase the signal strength, the antibody amplification protocol (FS450_0002) was used.

\section{Chip data processing}

Gene chips were processed with an Affymetrix GeneChip ${ }^{\oplus}$ Scanner 3000 7G (Affymetrix) and DAT image files of the microarrays were generated using GeneChip ${ }^{\star}$ Operating Software (GCOS 1.4; Affymetrix). Within GeneSpring ${ }^{\bullet}$ raw data were preprocessed including background adjustment, normalization, and summarization of probe sets, using the GeneChip ${ }^{\circ}$ Robust Multiarray Analysis (GCRMA). Genes whose signals were lower than background in all gene chips were filtered out, subsequently genes were filtered based on fold change. Statistical analysis on the gene expression profile were performed by using Fisher's analysis of variance (ANOVA). Profiles of genes significantly ( $\mathrm{p} \leq 0.001)$ up- or downregulated $(+/-1.3$-fold) in CD133+ D10 cells as compared to CD133- D10 cells were obtained. In addition, final gene expression data were analyzed using the Protein Analysis Through Evolutionary Relationships (PANTHER) classification system [34].

\section{Additional files}

Additional file 1: Phenotypical characterization of melanoma cel lines. Corresponding mean fluorescent intensities (MFI). MFI = signal (mAb) - signal (isotype control). No signal detected was indicated by (neg.) when $\mathrm{MFI}<1$

Additional file 2: Results of gene expression profiling. Table shows significantly ( $p \leq 0.001$ ) upregulated genes (>1.3-fold) compared to CD133- D10 cells. FC $=$ fold change of up-regulation; RefSeq $=$ References to multiple sequences; ChrLoc = chromosomal location. The gene CEACAM1 is provided as a triplet, the genes ENTPD and TPD52 as duplicates, respectively.

Additional file 3: Results of gene expression profiling. Table shows significantyl ( $p \leq 0.001$ ) down-regulated genes ( $>1.3$-fold) compared to CD133- D10 cells. FC = fold change of up-regulation; RefSeq = References to multiple sequences; ChrLoc = chromosomal location.

Additional file 4: Real-time rt-PCR results for MGP expression in CD133+ (black column) and CD 133- (white column) D10 cells. $\left(^{*}\right)=p \leq 0.05$.

Additional file 5: Primers and Probes. Gp100 = melanosomal matrix protein gp100; MART-1 = Melan-A/MART-1 = melanoma antigen 
recognized by $T$ cells; tyrosinase $=$ key enzyme in melanin biosynthesis; NY-ESO = cancer/testis antigen (see text)

Additional file 6: Gene expression assays* for real-time RT-PCR.

*TagMan ${ }^{\circledast}$ Gene Expression Assays (Assay-on-demand"; see Assay IDs), Applied Biosystems ([AB], Foster City, CA); hACTB = human ACTB (beta actin) endogenous control; NANOG = nanog homeobox; OCT4 = POU-domain transcription factor; SOX2 = SRY (sex determining region Y)-box 2; MAGE-A3 = melanoma antigen-A3 family; MGP = Matrix Gla protein .

Additional file 7: Results of FACSVantage ${ }^{\oplus}$ cell sorting of CD133+ and CD133- D10 cells. Fluorochrome-linked mAbs against CD133 (CD133/2PE) were used. A: Histogram B: dotplots.

\section{Abbreviations}

ABCG2: ATP-binding cassette, sub-family G (WHITE), member 2A; ABCA: ATP-binding cassette, sub-family A (ABC1); ANOVA: analysis of variance; BSA: Bovine serum albumin; CSC: Cancer stem cell; CD: Cluster of differentiation; CTA: Cancer/testis antigen; CTLA-4: Cytotoxic T-lymphocyte antigen-4 (CD152); DMEM: Dulbecco's modified Eagle Medium;

DNA: Deoxyribonucleic acid; EDTA: Ethylene diamine tetra acetic acid FACS: Fluorescent-activated cell sorting; gp100: Melanosomal matrix protein; HEPES: 4-(2-hydroxyethyl)-1-piperazineethanesulfonic acid; IGF-1: Insulin-like growth factor-1; IGFBP-3: Insulin-like growth factor-binding protein-3; IL2: Interleukin-2; MAA: Melanoma-associated antigens; (mAbs): Monoclonal antibodies; MAGE-3: Melanoma-associated antigen-3; Melan-A/MART1: Melanoma antigen recognized by T-cells; MFI: Mean fluorescence intensity; MGP: Matrix Gla protein; mM: Millimolar; NANOG: North american network operators' group (transcription factor); NEAA: Non-essential amino acid; NYESO: New York esophageal; OCT4: Octamer-binding transcription factor 4; RT-PCR: Reverse transcriptase-polymerase chain reaction; poly-HEMA: Poly (2-hydroxyethyl methacrylate); PFA: Paraformaldehyde; PANTHER: Protein analysis through evolutionary relationships; PBS: Phosphate-buffered saline; PROM1: Prominin 1 (CD133); PSG: Penicillin, streptomycin, and gentamycin: SOX2: SRY (sex determining region Y)-box 2 (transcription factor); TGF- $\beta$ : Transforming growth factor beta.

\section{Competing interests}

The authors declare that they have no competing interests.

\section{Authors' contributions}

RMZ conducted the in vitro experiments and wrote the paper. PK carried out the PCR and conducted the animal experiments. PD performed the microarrays. AK took care of the immunohistochemistry. HK carried out the statistical analysis and the literature review. AE carried out animal surgeries. NCG and FT supervised the project and edited the manuscript. All authors read and approved the final manuscript.

\section{Acknowledgements}

Experiments were partly funded by the Lower Saxonian Cancer Society "Niedersächsische Krebsgesellschaft e. v." The article processing charges are funded by the Deutsche Forschungsgemeinschaft (DFG), "Open Acess Publizieren".

\section{Author details}

'Department of Oral and Maxillofacial Surgery, Head \& Neck Oncology Laboratory, Hannover Medical School, Carl-Neuberg-Str. 1, Hannover D-30625, Germany. ${ }^{2}$ Division of Molecular Psychology, Life Sciences Training Facility (LSTF), Missionsstrasse 60/62, Basel CH-4055, Switzerland.

Received: 21 March 2013 Accepted: 1 August 2013

Published: 6 August 2013

\section{References}

1. Chen AY, Desantis C, Jemal A: US mortality rates for oral cavity and pharyngeal cancer by educational attainment. Arch Otolaryngol Head Neck Surg 2011, 11:1094-1099.

2. Rietschel P, Wolchok JD, Krown S, Gerst S, Jungbluth A, Busam K: Phase II study of extended-dose temozolomide in patients with melanoma. J Clin Oncol 2008, 14:2299-2304.

3. Garbe C, Hauschild A, Volkenandt M, Schadendorf D, Stolz W, Reinhold U: Evidence and interdisciplinary consensus-based German guidelines: surgical treatment and radiotherapy of melanoma. Melanoma Res 2008, 1:61-67.

4. Garbe C, Hauschild A, Volkenandt M, Schadendorf D, Stolz W, Reinhold U: Evidence-based and interdisciplinary consensus-based German guidelines: systemic medical treatment of melanoma in the adjuvant and palliative setting. Melanoma Res 2008, 2:152-160.

5. Garbe C, Garbe C, Hauschild A, Volkenandt M, Schadendorf D, Stolz W, Reinhold U: Short German guidelines: malignant melanoma. J Dtsch Dermatol Ges = Journal of the German Society of, Dermatology 2008, 6:S9-S14.

6. Turcotte S, Rosenberg SA: Immunotherapy for metastatic solid cancers. Adv Surg 2011, 45:341-360.

7. Chapman $P B$, et al: Improved survival with vemurafenib in melanoma with BRAF V600E mutation. N Engl J Med 2011, 26:2507-2516.

8. Hamburger A, Salmon SE: Primary bioassay of human myeloma stem cells. J Clin Invest 1977, 4:846-854.

9. Bonnet D, Dick JE: Human acute myeloid leukemia is organized as a hierarchy that originates from a primitive hematopoietic cell. Nat Med 1997, 7:30-737.

10. Mizrak D, Brittan M, Alison MR: CD133: molecule of the moment. J Path 2008, 214:3-9

11. Al-Haij M, Wicha MS, Benito-Hernandez A, Morrison SJ, Clarke MF: Prospective identification of tumorigenic breast cancer cells. Proc Nat/ Acad Sci U S A 2003, 7:3983-3988.

12. Carmeliet $P$, Jain RK: Angiogenesis in cancer and other diseases. Nature 2000, 6801:249-257.

13. Pouysségur J, Dayan F, Mazure NM: Hypoxia signalling in cancer and approaches to enforce tumour regression. Nature 2006, 7092:437-443.

14. Fang D, Nguyen TK, Leishear K, Finko R, Kulp AN, Hotz S: A tumorigenic subpopulation with stem cell properties in melanomas. Cancer Res 2005, 20:9328-9337.

15. Tavaluc RT, Hart LS, Dicker DT, El-Deiry WS: Effects of low confluency, serum starvation and hypoxia on the side population of cancer cell lines. Cell Cycle 2007, 20:2554-2562

16. Zhou J, Zhang Y: Cancer stem cells: Models, mechanisms and implications for improved treatment. Cell Cycle 2008, 10:1360-1370.

17. Schmidt $\mathrm{P}$, Abken $\mathrm{H}$ : The beating heart of melanomas: a minor subset of cancer cells sustains tumor growth. Oncotarget 2011, 4:313-320.

18. Schatton T, Murphy GF, Frank NY, Yamaura K, Waaga-Gasser AM, Gasser M: Identification of cells initiating human melanomas. Nature 2008, 7176:345-349.

19. Clevers $\mathrm{H}$ : The cancer stem cell: premises, promises and challenges. Nat Med 2011, 3:313-319.

20. Monzani E, Facchetti F, Galmozzi E, Corsini E, Benetti A, Cavazzin C: Melanoma contains CD133 and ABCG2 positive cells with enhanced tumourigenic potential. Eur J Cancer 2007, 5:935-946.

21. La Porta CAM, Porro D, Comolli R: Higher levels of melanin and inhibition of cdk2 activity in primary human melanoma cells WM115 overexpressing nPKCdelta. Melanoma Res 2002, 4:297-307.

22. Hyslop L, Stojkovic M, Armstrong L, Walter T, Stojkovic P, Przyborski S: Downregulation of NANOG induces differentiation of human embryonic stem cells to extraembryonic lineages. Stem Cells 2005, 8:1035-1043.

23. Clark AT, Rodriguez RT, Bodnar MS, Abeyta MJ, Cedars MI, Turek PJ: Human STELLAR, NANOG, and GDF3 genes are expressed in pluripotent cells and map to chromosome $12 \mathrm{p} 13$, a hotspot for teratocarcinoma. Stem Cells 2004, 2:169-179.

24. Lin T, Chao C, Saito S, Mazur SJ, Murphy ME, Appella E, Xu Y: p53 induces differentiation of mouse embryonic stem cells by suppressing Nanog expression. Nat Cell Biol 2005, 2:165-171.

25. Civenni G, Walter A, Kobert N, Mihic-Probst D, Zipser M, Belloni B, Seifert B, Moch H, Dummer R, van den Broek M, Sommer L: Human CD271-positive melanoma stem cells associated with metastasis establish tumor heterogeneity and long-term growth. Cancer Res 2011, 8:3098-3109.

26. Lai CY, Schwartz BE, Hsu MY: CD133+ melanoma subpopulations contribute to perivascular niche morphogenesis and tumorigenicity through vasculogenic mimicry. Cancer Res 2012, 72:5111-5118.

27. Roesch A, Fukunaga-Kalabis M, Schmidt EC, Zabierowski SE, Braford PA Vultur A: A temporarily distinct subpopulation of slow-cycling melanoma cells is required for continuos tumor growth. Cell 2010, 141:583-594.

28. Shmelkov SV, Butler JM, Hooper AT, Hormigo A, Kushner J, Milde T, St Clair R, Baljevic M, White I, Jin DK, Chadburn A, Murphy AJ, Valenzuela DM, Gale NW, Thurston G, Yancopoulos GD, D'Angelica M, Kemeny N, Lyden D, Rafii S: CD133 expression is not restricted to stem cells, and both CD133+ 
and CD133- metastatic colon cancer cells initiate tumors. J Clin Invest 2008, 118(6):2111-2120.

29. Hilmi C, Larribere L, Giuliano S, Bille K, Ortonne JP, Ballotti R, Bertolotto C IGF1 promotes resistance to apoptosis in melanoma cells through an increased expression of BCL2, BCL-X(L), and survivin. J Invest Dermatol 2008, 6:1499-1505

30. Frisan T, Levitsky V, Masucci M: Limiting dilution assay. Methods Mol Biol 2001, 174:213-216.

31. Spagnoli GC, Schaefer C, Willimann TE, Kocher T, Amoroso A, Juretic A: Peptide-specific CTL in tumor infiltrating lymphocytes from metastatic melanomas expressing MART-1/Melan-A, gp100 and Tyrosinase genes: a study in an unselected group of HLA-A2.1-positive patients. Int J Cancer 1995, 5:309-315.

32. Spagnoli GC, Kloth J, Terracciano L, Trutmann M, Chklovskaia E, Remmel E, Noppen C, Zajac P, Kocher T, Heberer M: FLT3 ligand gene expression and protein production in human colorectal cancer cell lines and clinical tumor specimens. Int J Cancer 2000, 86:238-243.

33. Pfaffl MW: A new mathematical model for relative quantification in realtime RT-PCR. Nucleic Acids Res 2001, 1(9):29-45.

34. Thomas PD, Kejariwal A, Campbell MJ, Mi H, Diemer K, Guo N, Ladunga I, Ulitsky-Lazareva B, Muruganujan A, Rabkin S, Vandergriff JA, Doremieux O: PANTHER, a browsable database of gene products organized by biological function, using curated protein family and subfamily classification. Nucl Acids Res 2003, 31:334-341.

doi:10.1186/1475-2867-13-78

Cite this article as: Zimmerer et al.: Functional features of cancer stem cells in melanoma cell lines. Cancer Cell International 2013 13:78.

\section{Submit your next manuscript to BioMed Central and take full advantage of:}

- Convenient online submission

- Thorough peer review

- No space constraints or color figure charges

- Immediate publication on acceptance

- Inclusion in PubMed, CAS, Scopus and Google Scholar

- Research which is freely available for redistribution 